\title{
Mechanism of fluid transport across corneal endothelium and other epithelial layers: a possible explanation based on cyclic cell volume regulatory changes
}

Maintenance of normal corneal transparency and the possible loss of it in disease continue to be relevant clinical issues. The possibility of control of corneal hydration (hence transparency) by the active intervention of the corneal limiting layers was raised for the first time by Davson in an article in the $B F O$ in $1949 .{ }^{1}$ Thanks to the discovery of endothelial fluid transport by Maurice $^{2}$ and the contributions of, among others, Mishima, ${ }^{3}$ Dikstein, ${ }^{4}$ Fischbarg, ${ }^{5}$ Hodson, ${ }^{6}$ Green, ${ }^{7}$ Edelhauser, ${ }^{8}$ Wiederholt, ${ }^{9}$ Riley, ${ }^{10}$ Bonanno, ${ }^{11}$ and their colleagues, it is clear that the corneal endothelium dehydrates the cornea and contributes to the maintenance of its transparency.

Such understanding and the fact that endothelial cells do not divide in humans has led to substantial advances in the way the endothelial layer is treated during surgery or is preserved before transplantation. Still, endothelial loss of function or decompensation continues to be a clinical problem, which raises the question of whether what has been gained in recent basic knowledge can now be put to renewed clinical or therapeutic use. In this context, after nearly five decades since the modern chapter of endothelial function began, it seems fitting to ask once more how this layer might function.

\section{Fluid transport in general and in the corneal endothelium}

The endothelium is but one example of many fluid transporting epithelial layers in the rest of the eye, the human body, and nature in general. Aside from discharging crucial functions, there is another peculiarity these layers share-it is not known how they transport fluid. A seminal observation was made by Curran and Solomon ${ }^{12}$ that translayer transport of electrolytes precedes and results in translayer water transfer. However, the precise cellular mechanism by which electrolyte transport is coupled to water transfer ('solute-solvent coupling') has remained obscure. ${ }^{13}$ It is an important question, arguably the major remaining unsolved problem in epithelial physiology, and it has special relevance to the eye, which contains a large mass of water and depends crucially on transepithelial water movements. Based on physiological observations and on the distribution of water channel proteins, the eye has many epithelial layers for which fluid transfer has so far been recognised or suggested $^{14}$ to be an important function (corneal epithelium, corneal endothelium, conjunctival epithelium, iris epithelium, ciliary epithelium, lens epithelium, trabecular meshwork, Schlemm's canal endothelium, and retinal pigment epithelium). Last, but not least, the dysfunction of several of these layers is either known or suspected to be involved in diseases (corneal endothelium in dystrophies; ciliary body and trabecular meshwork in glaucoma; retinal pigment epithelium in retinal detachments, macular degeneration, as well the pathomechanism of central serous choroidopathy), so this question is relevant to a broad area of ocular physiopathology.

All theories to explain the coupling between solute and solvent movements across epithelia have met objections. The once popular standing gradient hypothesis ${ }^{15}$ was held to be insufficient. ${ }^{16}$ Later on, as the relatively high osmotic permeability of some epithelial cell membranes became apparent, ${ }^{17}$ simple transcellular local osmosis was proposed as an explanation ${ }^{17}$; however, theoretical treatments ${ }^{18-20}$ eventually showed that local osmosis could produce only hypertonic but not isotonic fluid transport. This led to an alternative proposal based on electro-osmotic coupling of a recirculating electrolyte, ${ }^{20}$ but such a mechanism could not account for some experimental results. ${ }^{21}$ This review proposes a novel idea-epithelial layers that transport fluid might do so via a cell volume driven pulsatile mechanism that would be essentially a particular case of cell volume regulation. The corneal endothelium is the primary example here, but most if not all of the concepts below may be directly applicable to all other fluid transporting layers in the eye and the rest of the body.

\section{Model of pulsatile fluid transport}

The requirements of a model of pulsatile fluid transport are: (1) clock or cell volume dependent trigger; (2) pattern of polarisation; and (3) water channels.

We hypothesise that transendothelial fluid transport is pulsatile, and is based on cyclic, sequential transient activation of two different sets of osmolyte (ion and solute) transporters and/or channels triggered by changes in cell volume. One set of transporters/channels would serve for cell gain of osmolyte and fluid, and would be the same set the cell utilises during a regulatory volume increase response (RVI set); conversely, the second set of transporters/channels would serve for cell loss of osmolyte and fluid, and would be the same set the cell utilises during a regulatory volume decrease response (RVD set). For instance, it has been noted that in non-pigmented epithelial cells, basal $\mathrm{K}^{+}$and $\mathrm{Cl}^{-}$channels are likely to be connected with formation of aqueous humour, and $\mathrm{K}^{+}$and $\mathrm{Cl}^{-}$channels are presumed critical for RVD. ${ }^{22}$ The current proposal builds on a number of pre-existing observations such as the one above, and places them in a novel framework. Sets of transporters and channels that get separately activated during RVI and RVD (RV sets) are common to most cells; what would distinguish transporting epithelia is that in them these sets would be separately located, one on the basolateral and the other one in the apical cell membranes. Epithelial cells are known to be polarised; for pulsatile fluid transport to work, they would be polarised with the RVI set on one side of the cell, and the RVD set on the other side. As an obvious corollary, in secretory epithelia the RVI set would be basolateral and the RVD set 
apical, while absorptive epithelia would have the RVI set apical and the RVD set basolateral.

ACTIVATION

Although cells may have the capability to undergo damped volume oscillations, to ensure continuous operation other mechanisms need to be present to keep cell volume from merely stabilising at its set point. A clock to activate the cycles periodically is a possibility; another one is to assume that the RVI and RVD sets are modulated by the cell volume. We have verified that this last hypothesis leads to a model that can exhibit a variety of dynamic behaviours, including sustained oscillations in cell volume yielding isotonic fluid transport (J Fischbarg, J A Hernandez, in preparation). In actual epithelia, activation mechanisms are presumably more complex, including perhaps a cellular or tissue clock driving separate sequential activation and deactivation of RVI and RVD related transporters.

TRANSIENT VERSUS STEADY STATE FLOWS

Separate sequential activation (followed by deactivation) of the separate RV sets would generate equally transient local transmembrane osmotic gradients, and transient fluid flows would enter or leave the cell driven by those gradients. This marks a difference with cell volume regulation. For the limited goal of RVI or RVD in cells in general, only steady state continuous gain (loss) of osmolytes is required as the cell adjusts its water contents eventually with no special time frame or sidedness. But the transient, cyclic, volume regulatory nature of the osmotic flows postulated here is conceptually very different from the steady state local osmosis that has been mentioned so far as an explanation for solute-solvent coupling or fluid transport. Ussing and Eskesen ${ }^{20}$ have presented a powerful theoretical objection showing that vectorial fluid transport based on steady state transcellular local osmosis occurring simultaneously across both the basolateral and apical membranes cannot lead to isotonic coupling owing to the viscous retardation that cell macromolecules would impart on transcellular water flow. Even without such objection, for a steady state mechanism to operate, the simultaneous entry and exit of solutes across the basolateral and apical membranes would need to be exquisitely coordinated to maintain cell volume. No mechanism of cellular control has been identified so far that could account for such a delicate balance. On the other hand, in dramatic contrast, if one simply postulates that the basolateral and apical transport systems are activated (and subsequently deactivated) in a temporal sequence by volume regulatory mechanisms, the much studied mechanisms of cell signalling inherent to volume regulation become immediately available to perform such tasks quite well, as detailed below.

CENTRAL ROLE OF WATER CHANNELS

So far, the cyclic activation of transporters and channels proposed above would result in alternate osmotic movements across both cell ends, and pulsatile fluid transport. Precisely how much fluid could follow the osmolytes across the membranes in a given time frame is quite another matter; models of steady state local osmosis uniformly predict transport of somewhat hypertonic fluid, whereas physiological fluids are generally secreted isotonically. The presence of water channels in the cell membranes would therefore be central for efficient osmotic coupling between solute and solvent movements, leading to isotonic transport. Since the transient gradients created would dissipate fairly quickly by diffusion, a close temporal connection between osmolyte flows and water flows would be possible only if the cell membranes would have a requisite high osmotic permeability made possible by the presence
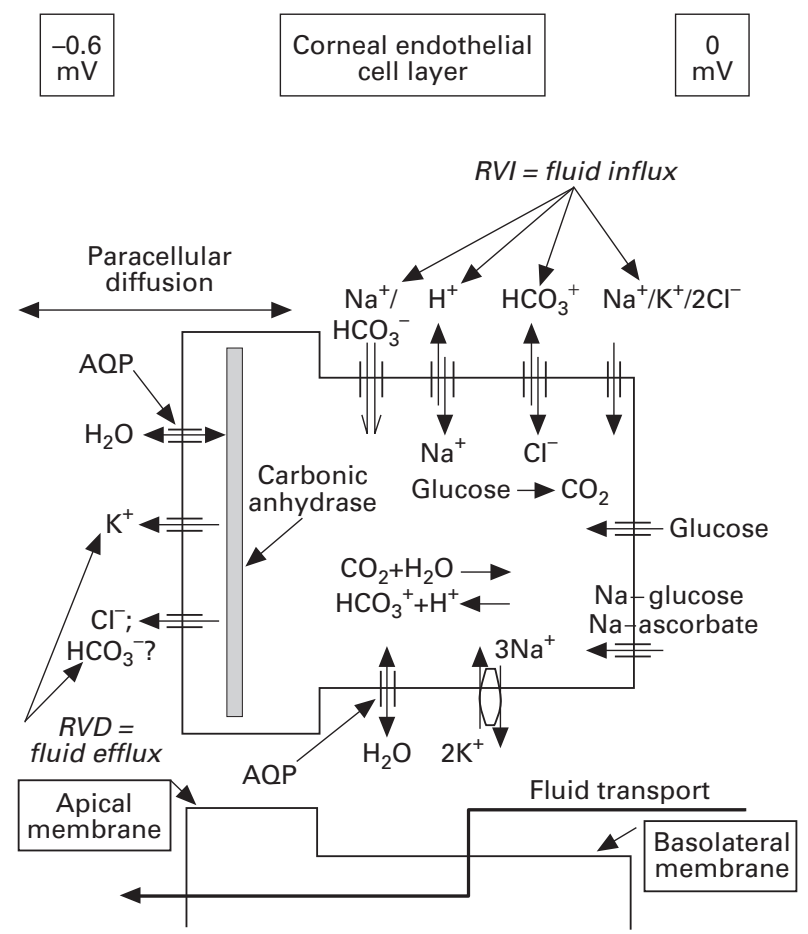

Figure 1 A corneal endothelial cell with receptors to adenosine, acetylcholine, and platelet activating factor, and the cell signalling cascades that would presumably follow the binding of such compounds. The cell would be polarised, with the transporters and/or channels involved in regulatory volume increase (RVI) located in the basolateral membrane, and those for regulatory volume decrease (RVD) in the apical membrane.

These two sets of transporters/channels would be activated each by a different signalling cascade; one possible arrangement is shown, with protein kinase $A$ triggering $R V I$ and protein kinase $C$ triggering $R V D$. $A Q P=$ aquaporins.

of water channels. Although a role for high membrane osmotic permeability has been historically linked with epithelial fluid transport, that notion could not be confirmed until recently. Water channels were not identified until $1992,{ }^{23}$ and their distribution began to be clarified only in 1993. They turned out to be present, by and large, only in cells for which water movement was a central functional attribute. ${ }^{24}{ }^{25}$ For instance, water channels were found only in those sections of the nephron permeable to water; this constitutes strong evidence for transmembrane, transcellular water movements.

\section{Identity of proteins in the endothelial RVI and RVD sets}

The proteins in question do not appear drastically different from those found to be involved in regulatory volume responses in other cells. RVI might involve activation of basolaterally located $\mathrm{Cl}^{-} / \mathrm{HCO}_{3}{ }^{-}$exchangers, $\mathrm{Na}^{+} / \mathrm{H}^{+}$exchangers, $\mathrm{Na}^{+}-\mathrm{K}^{+}-2 \mathrm{Cl}^{-}$cotransporters, $\mathrm{Na}^{+}-\mathrm{HCO}_{3}$ cotransporters, and so on. RVD in turn might involve activation of apically located volume dependent $\mathrm{K}^{+}$and $\mathrm{Cl}^{-}$ channels, or $\mathrm{KCl}$ cotransporters in those cells that express them. Additional channels and/or transporters may intervene to maintain homeostasis for intracellular $\mathrm{Ca}^{2+}$, and the $\mathrm{Na}^{+} / \mathrm{K}^{+}$-ATPase would maintain the $\mathrm{Na}^{+}$gradient necessary for driving the $\mathrm{Na}^{+}$dependent transporters. Such postulation is illustrated in the model of Figure 1.

Cytoskeleton and signalling: cell volume as controlling factor

In parallel with the advances on the presence and distribution of water channels, the cytoskeleton has emerged as a highly organised network charged with maintaining cell shape and size. As such, it is capable of reacting to stimuli 
such as cell volume changes with signals that cascade through the cell and lead to corrective responses. The integrin molecular assemblies present in cell membranes constitute promising candidates for a role in the control of cell volume and fluid transport. There is evidence that they generate chemical signals if they are either brought closer or pulled apart, ${ }^{26}$ as would happen during cellular volume changes.

There is evidence that cell signalling is connected with fluid secretion. Cholera toxin stimulates cerebrospinal ${ }^{27}$ and cochlear $^{28}$ fluid production, presumably via a cAMP pathway. Similarly, cAMP, 5-hydroxytryptamine, and $\mathrm{Ca}^{2+}$ mobilising agents stimulate salivary gland secretion by salivary glands. ${ }^{29} 30$ The corneal endothelial fluid secretion is also connected to signalling; adenosine stimulates fluid transport, ${ }^{31}$ presumably via receptors that stimulate adenyl cyclase $^{32}$ through a $G$ protein ${ }^{33}$; such results appear consistent with an adenosine triggered cascade leading to protein kinase A (PKA) activation. In addition, platelet activating factor, known to activate the protein kinase $\mathrm{C}$ (PKC) signalling pathway in other systems, inhibits endothelial fluid transport. ${ }^{34}$ It is also worth mentioning that a muscarinic receptor has been recently located in corneal endothelium, ${ }^{35}$ and that acetylcholine increases the rate of rabbit stromal deturgescence ${ }^{36}$ and the transendothelial electrical potential difference. ${ }^{37}$ These findings may be connected with the classic stimulation of fluid transport by acetylcholine via a signalling cascade in salt gland. ${ }^{38}$ It is worth noting that, in the steady state, the cascade presumably triggered by adenosine (PKA) stimulates fluid transport, ${ }^{33}$ while that which would follow platelet activating factor treatment (PKC) inhibits fluid transport. ${ }^{34}$ That difference might arise if each cascade activates (or deactivates) a different set of membrane proteins. Thus, sustained PKA activation might lead to increased electrolyte $(\mathrm{NaCl}, \mathrm{KCl}$ ?) and fluid influx across the basolateral membrane and the layer, while sustained PKC activation might lead to depletion of cell electrolytes and inhibition of fluid transport.

\section{Oscillatory phenomena in pulsatile fluid transport: some precedents}

From the above, if the cascades are active during fluid transport, optimal efficiency would best be achieved if they acted with temporal separation, as in the cycle postulated here (Figs 2 and 3). In support of these notions, temporal changes in protein phosphorylation have been proposed to underlie cell volume regulatory phenomena. ${ }^{39} 40$ In addition, evidence has accumulated during the past few years that a variety of processes in transporting epithelial cells are oscillatory. Examples are oscillations in cell volume and cell $\left[\mathrm{Ca}^{2+}\right]^{41}$ or cyclic variations in ciliary epithelial cell conductance, ${ }^{42}$ and oscillatory changes in electrical potential difference across anterior lens. ${ }^{43}$ Some older observations are also in line with this picture. Fluid transport across corneal endothelium has been measured with a time resolution of some 30 seconds and a volume resolution of 3-5 nl. Interestingly, records of rate of fluid transport across in vitro animal preparations ${ }^{31}$ or cultured bovine corneal endothelial cells ${ }^{44}$ are 'noisy'. Instead, control recordings of fluid flowing across an inanimate membrane $^{31}$ are noticeably more stable. Such noise remains unexplained; although not, in itself, evidence for oscillations it seems consistent with them. In another case, we reported that brief osmotic challenge primed subsequent transendothelial fluid transport $\mathrm{t}^{45}$ for as long as an hour. That observation has remained unexplained but in the current framework if, before osmotic challenge, some endothelial cells may have been inactive, the osmotic challenge may have activated them and led to enhanced fluid

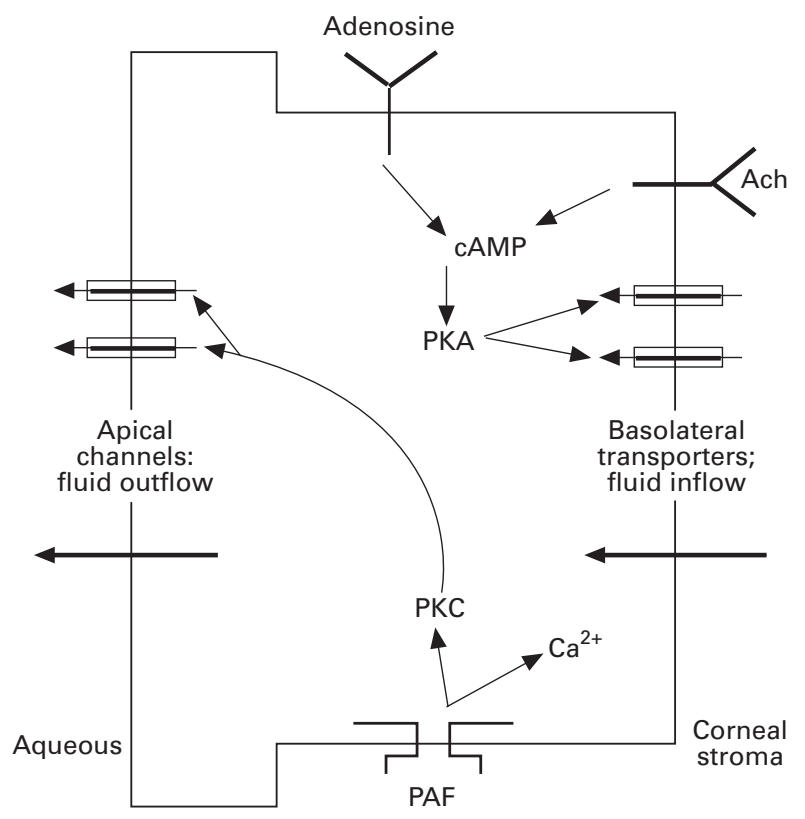

Figure 2 A model for fluid transport across corneal endothelium. Water passage is shown across aquaporins or water channels. The distribution indicated for the membrane proteins is assumed, except for the $\mathrm{Na}^{+}$pump (long known to be basolateral) and the aquaporins, since our own evidence (F Li, K Kuang, $S$ Nielsen, $\mathcal{F}$ Fischbarg, in preparation) places them in both apical and basolateral membranes. With the cell polarised as shown, fluid transport from stroma to aqueous could result from successive volume increase-decrease cycles analogous to those in RVI and RVD. PAF = platelet activating factor.

transport. Since endothelial cells regulate their volume in just a few minutes, for fluid transport to remain stimulated much longer a self sustained sequence of oscillatory cell signalling and volume changes offers itself as an explanation. In summary, as noted above, many elements seem in place to account for fluid transport in terms of a succession of volume regulatory events triggered alternately across the basolateral and apical membranes of a polarised endothelial cell. Such cyclic mechanism has been recently mentioned briefly as a possible explanation for fluid transport in connection with some of our own findings. ${ }^{34}$

\section{Other results and current perspective}

The current proposal also provides a basis to explain or reinterpret other past observations. For instance, repeated and cogent reports of drag of paracellular solutes induced by solvent flow across leaky junctions of fluid transporting epithelia ${ }^{46-48}$ may be explained if periodic variations in cell volume would lead to changes in the hydrostatic pressure in the intercellular spaces and consequent fluid expulsion and/or aspiration across leaky junctions. In the present context, such paracellular movements would take place in addition to the transcellular water movements postulated here. In another area, a report of cotransport of water and osmolytes across membrane proteins of choroid plexus epithelium ${ }^{49}$ presents an intriguing vision of the molecular nature of water transfers. Presumably that mechanism would not be the only one, since the presence of water channels in fluid transporting cells definitely suggests classic local osmosis.

Practically all assumptions made here can be tested. The pattern of polarisation of membrane proteins is one example, and the oscillations in the signalling cascades or in cell volume is another one. The current model (Fig 1) envisages transfer of $\mathrm{KCl}$ across basolateral and apical membranes as the main osmolyte driving fluid flow. If so, the net transport of $\mathrm{HCO}_{3}{ }^{-}$reported to exist across the endothelium ${ }^{67}$ would require an alternative explanation. 


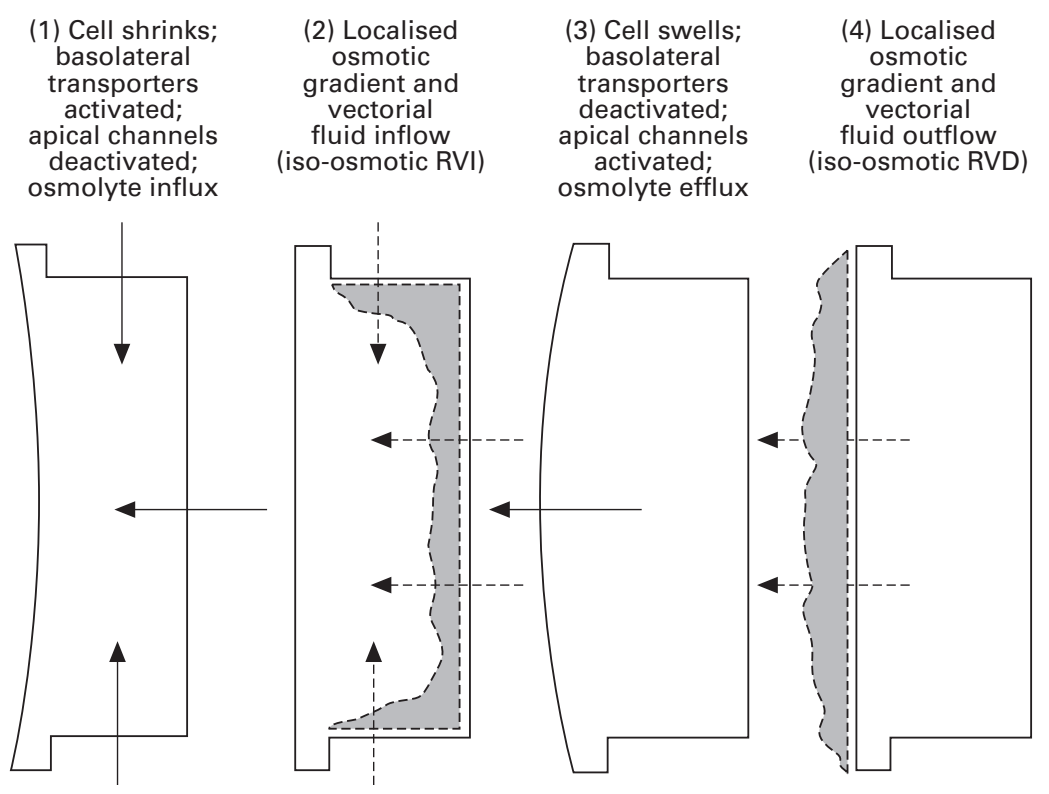

Figure 3 Schematic depiction of the temporal events postulated for a cycle of pulsatile endothelial fluid transport. Transient local osmotic gradients are denoted by the shading indicating osmolyte buildup on one side of the membrane (the concomitant depletion on the other side of the membrane is omitted). Osmolyte flux, solid arrows; water flow, broken arrows.

There may be a $\mathrm{Na}^{+}-\mathrm{HCO}_{3}{ }^{-}$cotransporter at the apical membrane, ${ }^{9}$ or the cell volume dependent apical $\mathrm{Cl}^{-}$channels postulated here as part of the RVD set would also allow $\mathrm{HCO}_{3}{ }^{-}$efflux. Interestingly, a recent re-examination of $\mathrm{HCO}_{3}^{-}$transport by ciliary epithelium produced evidence for net $\mathrm{Cl}^{-}$but not $\mathrm{HCO}_{3}{ }^{-}$fluxes. ${ }^{50}$ As for the polarisation pattern, no glaring contradictions have been uncovered between current assumptions and the literature in a survey under way that we will report on elsewhere. To cite just a recent example, a volume sensitive $\mathrm{Cl}^{-}$conductance in retinal pigment epithelium appears located at its basolateral membrane, ${ }^{51}$ precisely where the current model would predict its placement in that absorptive epithelium.

\section{Could these ideas help endothelial therapy?}

Obviously understanding why the endothelial layer stops functioning might allow one to develop countermeasures. Still, if the present ideas are correct, fluid transport would not be a simple process but would rather depend on a combination of cell features including its cytoskeleton, signalling cascades, and the activation of a host of volume regulatory membrane proteins. Any of these elements might conceivably fail separately and thus give rise to decompensation.

The best known reason for human endothelium to fail involves progressive loss of cells. As the surviving cells strain to cover the gaps by flattening and increasing their diameter, they reach a point at which their change in shape and volume interferes with their function. In light of the current proposal, failure to transport fluid might be due to factors such as, for example, (a) the distortion in shape might affect cytoskeletal architecture enough to interfere with (i) the triggering of the signalling cascades that contribute to volume regulation (loss of signalling), or (ii) the mechanisms of transport that send each protein to its appointed destination in a polarised cell (loss of polarisation); (b) the cells would become too thin for any osmolyte gradient to be restricted to the membrane on one side of the cell; gradients would propagate and quickly affect both membranes leading to fluid flow into or out of the cells in two directions simultaneously, which is the opposite of the normal vectorial (stroma to aqueous) fluid flow.

With current knowledge, it seems exceedingly difficult to suggest a 'magic bullet' that would remedy the potential deficits (a) or (b). What might be somewhat more within experimental scope would be to continue current attempts to find out why these cells do not divide in humans, and set about remedying that. With luck, there may be a single gene that needs to be turned on (or off). Then again, the turn on mechanism might involve an array of genes no less complex than those leading to the expression of all the proteins involved in signalling and volume regulation. Whichever the case, more information is required, and it is hoped that these ideas may help direct future research.

This work was supported by USPHS grant EY06178 and by Research to Prevent Blindness, Inc.

\section{JORGE FISCHBARG}

Departments of Physiology and Cellular Biophysics, and

Ophthalmology, College of Physicians and Surgeons, Columbia

University, New York, NY 10032, USA

1 Davson H. Some considerations on the salt content of fresh and old ox cornea. Br f Ophthalmol 1949;33:175-82.

2 Maurice DM. The location of the fluid pump in the cornea. F Physiol (Lond)

3 Trenberth SM, Mishima S. The effect of ouabain on the rabbit corneal Trenberth SM, Mishima S. The effect of ouabain on
endothelium. Invest Ophthalmol Vis Sci 1968;7:44-52.

4 Dikstein S, Maurice DM. The metabolic basis of the fluid pump in the cornea. F Physiol (Lond) 1972;221:29-41.
constein S, The

5 Fischbarg J, Lim JJ. Role of cations, anions and carbonic anhydrase in fluid transport across rabbit corneal endothelium. F Physiol (Lond) 1974;241: 647-75.

6 Hodson S, Miller F. The bicarbonate ion pump in the endothelium which regulates the hydration of the rabbit cornea. F Physiol (Lond) 1976;263: 563-77.

7 Hull DS, Green K, Boyd M, Wynn HR. Corneal endothelial bicarbonate transport and the effect of carbonic anhydrase inhibitors on endothelial permeability, fluxes and thickness. Invest Ophthalmol Vis Sci 1977;16:88392.

8 Geroski DH, Edelhauser HF. Quantitation of $\mathrm{Na} / \mathrm{K}$ ATPase pump sites in the rabbit corneal endothelium. Invest Ophthalmol Vis Sci 1984;25:105660.

9 Jentsch TJ, Keller SK, Koch M, Wiederholt M. Evidence for coupled transport of bicarbonate and sodium in cultured bovine corneal endothelial port of bicarbonate and sodium in

10 Riley MV, Winkler BS, Czajkowski CA, Peters MI. The roles of bicarbonate and $\mathrm{CO}_{2}$ in transendothelial fluid movement and control of corneal thickness. Invest Ophthalmol Vis Sci 1995;36:103-12. 
11 Bonanno JA, Giasson C. Intracellular $\mathrm{pH}$ regulation in fresh and cultured bovine corneal endothelium. II. $\mathrm{Na}^{+}: \mathrm{HCO}_{3}{ }^{-}$cotransport and $\mathrm{Cl}^{-} / \mathrm{HCO}_{3}{ }^{-}$
exchange. Invest Ophthalmol Vis Sci 1992;33:3068-79.

12 Curran PF, Solomon AK. Ion and water fluxes in the ileum of rats. $7 \mathrm{Gen}$ Physiol 1957;41:143-68.

13 Whittembury G, Reuss L. Mechanisms of coupling of solute and solvent transport in epithelia. In: Seldin DW, Giebisch G, eds. The kidney: physiology and pathophysiology. 2nd ed. New York: Raven Press, 1992:31760.

14 Fischbarg J. A rapidly emerging field: water channel proteins in the eye. Invest Ophthalmol Vis Sci 1995;36:758-63.

15 Diamond JM, Bossert WH. Standing-gradient osmotic flow. A mechanism for coupling of water and solute transport in epithelia. f Gen Physiol 1967; 50:2061-83.

16 Hill AE. Solute-solvent coupling in epithelia: a critical examination of the standing-gradient osmotic flow theory. Proc $R$ Soc Lond B Biol Sci 1975;190:99-114.

17 Persson BE, Spring KR. Gallbladder epithelial cell hydraulic water permeability and volume regulation. F Gen Physiol 1982;79:481-505.

18 Gonzalez E, Carpi-Medina P, Whittembury G. Cell osmotic water permeability of isolated rabbit proximal straight tubules. Am 7 Physiol 1982;242:F321-30.

19 Fischbarg J. On the theory of solute solvent coupling in epithelia. In: Benga $\mathrm{G}$, ed. Water transport in biological membranes. Boca Raton, FL: CRC Press, 1989:153-67.

20 Ussing HH, Eskesen K. Mechanism of isotonic water transport $\mathrm{n}$ glands. Acta Physiol Scand 1989;136:443-54.

21 Kuang K, Cragoe EJ, Fischbarg J. Fluid transport and electro-osmosis across corneal endothelium. In: Ussing $\mathrm{HH}$, Fischbarg J, Sten Knudsen E Hviid Larsen E, Willumsen NJ, eds. Proc Alfred Benzon Symposium 34, 'Water transport in leaky epithelia'. Copenhagen: Munksgaard, 1993:69-79.

22 Yantorno RE, Carre DA, Coca-Prados M, Krupin T, Civan MM. Whole cell patch clamping of ciliary epithelial cells during anisosmotic swelling. $\operatorname{Am} \mathcal{f}$ Physiol 1992;262:C501-9.

23 Preston GM, Carroll WB, Guggino WB, Agre P. Appearance of water channels in Xenopus oocytes expressing red cell CHIP28 protein. Science 1992; 256:385-7.

24 Nielsen S, Smith BL, Christensen EI, Knepper MA, Agre P. CHIP28 water channels are localized in constitutively water-permeable segments of the channels are localized in constitutively
nephron. $\mathcal{F}$ Cell Biol 1993;120:371-83.

25 Hasegawa H, Zhang R, Dohrman A, Verkman AS. Tissue-specific expression of mRNA encoding rat kidney water channel CHIP28k by in expression of mRNA encoding rat kidney water channel CHIP28
situ hybridization. Am ₹ Physiol Cell Physiol 33 1993;264:C237-45.

26 Schwartz MA, Ingber DE. Integrating with integrins. Mol Biol Cell 1994;5: 389-93.

27 Epstein MH, Feldman AM, Brusilow SW. Cerebrospinal fluid production: stimulation by cholera toxin. Science $1977 ; 196: 1012-3$.

28 Feldman AM, Bittner HR, Brusilow SW. Measurement of the hydrostatic pressures of the cochlear compartments. Neurol Res 1979;1:11-8.

29 Fain JN, Berridge MJ. Relationship between phosphatidylinositol synthesis and recovery 5 5-hydroxytryptamine responsive- $\mathrm{Ca}^{2+}$ flux in blowfly salivary gland. Biochem f 1979;180:655-61.

30 Streb H, Irvine RF, Berridge MJ, Schulz I. Release of $\mathrm{Ca}^{2+}$ from a nonmitochondrial intracellular store in pancreatic acinar cells by inositol-1,4,5trisphosphate. Nature 1983;306:67-9.

31 Fischbarg J, Lim JJ, Bourguet J. Adenosine stimulation of fluid transport across rabbit corneal endothelium. $7 \mathrm{Membr}$ Biol 1977;35:95-112.

32 Walkenbach RJ, Chao W-TH. Adenosine regulation of cyclic AMP in corneal endothelium. F Ocul Pharmacol 1985;1:337-42.
33 Riley MV, Winkler BS, Starnes CA, Peters MI. Adenosine promotes regulation of corneal hydration through cyclic adenosine monophosphate. Invest Ophthalmol Vis Sci 1996;37:1-10.

34 Zhu Z, Kuang K, Kang F, Li J, Fischbarg J. Platelet activating factor inhibits fluid transport by corneal endothelium. Invest Ophthalmol Vis Sci 1996; 37:1899-906

35 Lind GJ, Cavanagh HD. Identification and subcellular distribution of muscarinic acetylcholine receptor-related proteins in rabbit corneal and Chinese hamster ovary cells. Invest Ophthalmol Vis Sci 1995;36:1492507.

36 Akiyama R, Kuang K, Chiaradia P, Roberts CW, Fischbarg J. Effects of acetylcholine, carbachol and mannitol on rabbit corneal endothelial function as assessed by corneal deturgescence. Graefes Arch Clin Exp Ophthal 1996; (in press).

37 Akiyama R, Kuang K, Koniarek JP, Chiaradia P, Roberts CW, Fischbarg J. Solutions containing miotic agents: effects on corneal transendothelial electrical potential difference. Graefes Arch Clin Exp Ophthal 1996; (in press).

38 Hokin MR, Hokin LE. The formation and continuous turnover of a fraction of phosphatidic acid on stimulation of $\mathrm{NaCl}$ secretion by acetylcholine in the salt gland. F Gen Physiol 1967;50:793-811.

39 Jennings ML, Schulz RK. Okadaic acid inhibition of $\mathrm{KCl}$ cotransport. Evidence that protein dephosphorylation is necessary for activation of transport by either cell swelling or N-ethylmaleimide. f Gen Physiol 1991; 97:799-817.

40 Grinstein S, Furuya W, Bianchini L. Protein kinases, phosphatases, and the control of cell volume. NIPS 1992;7:232-7.

41 Wong MM, Foskett JK. Oscillations of cytosolic sodium during calcium oscillations in exocrine acinar cells. Science 1991;254:1014-6. [Published erratum appears in Science 1991 Dec 6;254:1435.]

42 Stelling JW, Jacob TJ. Membrane potential oscillation from a novel combination of ion channels. Am f Physiol 1993;265:C720-7.

43 Alvarez LJ, Candia OA, Zamudio AC. Acetylcholine modulation of the short-circuit current across the rabbit lens. Exp Eye Res 1995;61:12940.

44 Narula PM, Xu M, Kuang K, Akiyama R, Fischbarg J. Fluid transport across cultured bovine corneal endothelial cell monolayers. Am f Physiol, Cell Physiol 31 1992;262:C98-C103.

45 Fischbarg J, Hofer GL, Koatz RA. Priming of the fluid pump by osmotic gradients across rabbit corneal endothelium. Biochim Biophys Acta gradients across $1980 ; 603: 198-206$.

46 Steward MC. Paracellular non-electrolyte permeation during fluid transport across rabbit gall-bladder epithelium. F Physiol (Lond) 1982;322:419-39.

47 Whittembury G, Malnic G, Mello-Aires M, Amorena C. Solvent drag of sucrose during absorption indicates paracellular water flow in the rat kidney proximal tubule. Pflugers Arch 1988;412:541-7.

48 Shachar-Hill B, Hill AE. Convective fluid flow through the paracellular system of Necturus gall-bladder epithelium as revealed by dextran probes. $\mathcal{F}$ Physiol (Lond) 1993;468:463-86.

49 Zeuthen T. Cotransport of $\mathrm{K}^{+}, \mathrm{Cl}^{-}$and $\mathrm{H}_{2} \mathrm{O}$ by membrane proteins from choroid plexus epithelium of Necturus maculosus. 7 Physiol (Lond) 1994;478:203-19.

$50 \mathrm{Mok} \mathrm{KH}$, To $\mathrm{CH}$. Chloride and bicarbonate ion transport across isolated bovine iris-ciliary body. Invest Ophthalmol Vis Sci (Suppl, ARVO Abstr) 1996;37, No 3:S1 108.

51 Gallemore RP, Maruiwa F, Takahira M, Hughes B, Hu JG, Bok D. Swellingactivated chloride conductance in cultured human retinal pigment epithelium. Invest Ophthalmol Vis Sci (Suppl, ARVO Abstr) 1996;37, No 3:S230. 